\title{
COMPETENCIA ORAL, LENGUAJE JURÍDICO Y TEORÍA DE LA ARGUMENTACIÓN
}

\author{
M. ${ }^{\text {a }}$ Pilar NúÑEz Delgado \\ Universidad de Granada \\ Lisett D. PÁEz CuBA \\ Universidad de Pinar del Río, Cuba
}

\section{RESUMEN}

En este trabajo se abordan las conexiones entre la competencia oral y la argumentación en el contexto concreto del lenguaje jurídico. Estas conexiones se basan en que la destreza en el uso de la lengua hablada adquiere un valor particular en materia jurídica, donde todavía una parte relevante de las actuaciones -las vistas y juicios- siguen siendo situaciones interactivas orales. A esto ha de añadirse que el ejercicio del derecho, desde la creación de la norma hasta su aplicación, es un acto propiamente argumentativo. Ambos aspectos se abordan desde una perspectiva diacrónica, partiendo de las aportaciones de la oratoria y la retórica clásicas, hasta llegar a las más recientes teorías sobre la argumentación de cuño pragmático y neorretórico, para desembocar en la revisión de las distintas versiones de la Teoría de la Argumentación Jurídica y sus principales postulados. Las conclusiones apuntan a la conveniencia de potenciar, en la formación de juristas, lo relacionado con la estructura del razonamiento de iure y el dominio de la oralidad.

PALABRAS CLAVE: argumentación, competencia oral, lenguaje jurídico, oratoria, retórica.

\section{ABSTRACT}

This paper addresses the connection between oral competence and the argumentation within the juridical language context. These connections are based on the idea that the ability to use oral language increases its value when related to juridical aspects, where a significant part of the legal actions -court hearing and trials- is still an oral interactive situation. In addition, it is important to consider that the legal process, from the rule regulation until its application, is basically an argumentative action. Both aspects are tackled from the diachronic perspective, starting from the classical rhetoric contributions to the most recent neo-rhetoric and pragmatic argumentative theories, resulting in the reviewing of the different 
Juridical Argumentative Theory versions and its principal postulate. Conclusions are leading to the benefit of empowering the de iure reasoning structure and the control of orality in the jurist professional career.

KEYWORDS: argumentation, juridical language, oral competence, oratory, rhetoric.

Fecha de recepción: 07/07/2017

Fecha de aceptación: 07/11/2017

Fecha de la versión definitiva: 07/12/2017

\section{INTRODUCCIÓN}

El acelerado avance científico y tecnológico del presente siglo, en el que el acceso a la información es casi ilimitado, no requiere de personas que acumulen saberes, sino más bien capaces de transformar la información en conocimiento y de aplicarlo en una pluralidad de contextos sociales y para fines variados. En este marco, la formación basada en competencias aparece como una exigencia de las políticas educativas públicas, centradas en los cuatro pilares propuestos por la UNESCO: aprender a conocer, aprender a hacer, aprender a vivir juntos y aprender a ser (Delors 1996). Es esta una concepción integradora, que no limita la competencia a la adquisición de conocimientos sino que resalta el desarrollo de habilidades y aptitudes como dimensiones del contenido de aprendizaje, así como su carácter situado, dado que las competencias solo pueden desarrollarse en y para contextos determinados. Además, combina una dimensión funcional, de uso, con otra metacognitiva, de reflexión sobre los procesos y los productos, que garantizan el dominio eficaz y la transferencia a nuevos entornos (Tobón 2010).

Entre las competencias básicas, sin duda ocupa un lugar destacado la competencia comunicativa. El concepto de competencia comunicativa tiene un amplio recorrido que arranca de los estudios teóricos de Chomsky (1965), Gumperz y Hymes (1972) o Canale y Swain (1980), los cuales se han visto completados con otros que han tratado de caracterizar aspectos específicos de esta, como ocurre con la competencia oral (Ong 1987; Núñez 2003; Abascal 2004; Dumais 2012).

La competencia oral, esencial en cualquier ámbito de la vida, adquiere un valor particular en materia jurídica. El ejercicio del derecho es un acto propiamente argumentativo -desde la creación de la norma hasta su aplicación- y con frecuencia oral. Reviste especial importancia para el jurista la comunicación oral eficiente de argumentos lógico-racionales y afectivoemotivos por su incidencia en el resultado de las decisiones judiciales.

El presente trabajo tiene como objeto sistematizar las concepciones teóricas sobre la competencia oral y la argumentación, con especial refe- 
rencia al lenguaje jurídico. Este constituye uno de los llamados lenguajes de especialidad, cuyos rasgos diferenciales radican en los temas de que se ocupa (las leyes, la jurisprudencia), en el ámbito de uso que le es propio (el del derecho), en las características pragmáticas y retóricas particulares de los géneros discursivos en que se plasma (alegato, sentencia, etc.) y en los rasgos lingüísticos que emplea (léxico específico, oraciones pasivas, arcaísmos, gerundios frecuentes, aforismos jurídicos, futuro de subjuntivo, etc.). En tal sentido, se parte de considerar que argumentar constituye una habilidad cognitivo-lingüística inherente al ejercicio de la profesión jurídica. Por ende, el estudio de la competencia oral en este contexto conforma un campo de interés tanto para los estudios lingüísticos como para los jurídicos, que comparten las mismas raíces históricas: la retórica y la oratoria clásicas.

\section{El CONCEPTO DE COMPETENCIA ORAL EN EL DERECHO: APORTACIONES DE LAS CIENCIAS DEL LENGUAJE}

El concepto de competencia es complejo, y su origen reciente, situado en el ámbito económico y laboral, dificulta trasladarlo con precisión a otros campos. Sin embargo, tras la acuñación inicial de Chomsky (1965), el concepto se comenzó a estructurar a partir de los años setenta del pasado siglo sobre la base de diversos avances provenientes de la lingüística, la etnografía de la comunicación, la pragmática o la psicolingüística, ciencias que han contribuido a explicar las características lingüísticas y el funcionamiento retórico del lenguaje jurídico, esencialmente argumentativo. Se identifica la competencia comunicativa como un conjunto de capacidades, conocimientos, habilidades, actitudes y aptitudes que permiten actuar con eficacia en un contexto comunicativo determinado, como «un saber hacer cosas con las palabras» (Lomas 2014: 11) en una comunidad de habla. En consecuencia, la competencia oral puede presentarse como «el conjunto de saberes y habilidades comunicativas que un hablante posee y utiliza en la interacción [oral] con otros hablantes» (Abascal 2004: 99). Este objeto

[...] fait entre autres appel à des habiletés cognitives et linguistiques. Il concerne autant la production que la compréhension ainsi que le verbal, le paraverbal (prosodie, pauses, etc.) et le non-verbal (regard, gestes, etc.). Il peut être la langue écrite oralisée (lecture et récitation), un parler contrôlé [...] ou la pensée spontanée vocalisée, en direct ou en différé, et peut être monogéré (fait seul) ou polygéré (fait à plusieurs). (Dumais 2012: 19)

El estudio de la competencia oral requiere del análisis del concepto de oralidad. Esta es caracterizada como «una capacidad comunicativa que configura modos de percibir, de pensar y, por supuesto, de expresar el mundo» (Núñez 2003: 218), y definida, en primer término, como «el fenómeno del 
flujo de la voz en la pronunciación de la palabra. Se refiere a la comunicación lingüística por medio de la voz» (Abascal 2004: 19).

La teoría de la oralidad de Abascal (2004: 19) establece que «el proceso y producto de la oralidad es el discurso oral» en sus diferentes géneros, ya sea una clase, un sermón o el conjunto de discursos o informes que componen un juicio, que es justamente el que nos interesa en este trabajo. Este modelo retórico de la oralidad lo componen, grosso modo, tres categorías globales: hablante, oyente y actividad. Sin embargo, audiencias, vistas y juicios son situaciones comunicativas muy complejas y, ante todo, polifónicas. Así, aplicando la teoría de la enunciación de Ducrot (1986), en una vista, el papel de enunciador (sujeto del enunciado) lo desempeñan los testigos, las otras voces del discurso; mientras la defensa y la acusación podrían considerarse emisores (sujetos empíricos que producen el discurso), pero también locutores, pues son sujetos de la enunciación en la medida en que hablan en representación de los litigantes. En su competencia oral influyen sus conocimientos, personalidad y ética, su experiencia, imagen y papel social... El jurista se perfila como un hablante público (por su ámbito de actuación) que debe demostrar competencias comunicativas -pragmática, sociolingüística, discursiva, funcional, etc.- en la proyección del discurso jurídico. Los oyentes serían la audiencia y el juez o tribunal, a quienes va dirigido el alegato forense, y que son quienes deben responder al hablante con hechos. Excluyendo las situaciones de declaración de los acusados o litigantes y de los testigos, que constituyen eventos comunicativos particulares dentro de otro mayor, el alocutario y el destinatario en una vista son el juez y, de existir, también el jurado; el público asistente sería el auditor, pues oye los enunciados sin que el locutor se dirija expresamente a él. Por último, la actividad está compuesta por un grupo de operaciones internas y externas que configuran el discurso oral del jurista litigante, quien debe comunicar su tesis con una adecuada oratoria y un empleo eficiente de argumentos jurídicos.

El uso oral del lenguaje en el derecho conlleva especial valor connotativo ligado al predominio de la argumentación jurídica ${ }^{1}$. A este respecto, cabe destacar las aportaciones de la pragmática, al estudiar el modo en que el contexto influye en la interpretación del significado. Tres teorías de orientación pragmática de especial interés en este punto son la teoría de la relevancia de Sperber y Wilson (1986), la de la argumentación lingüística de Anscombre y Ducrot (1983) y la pragma-dialéctica de van Eemeren y Grootendorst (2004) ${ }^{2}$.

\footnotetext{
${ }^{1}$ Cabe mencionar en este punto la inclusión que hace Weston de un capítulo sobre argumentos orales en la edición de 2009 [2011] de Las claves de la argumentación.

${ }^{2}$ También Plantin (1968) analiza la argumentación desde presupuestos pragmáticos con especial atención a la interacción y a situaciones argumentativas de la vida cotidiana.
} 
La teoría de la relevancia trata la interpretación de los enunciados como un proceso cognitivo de tipo ostensivo-inferencial. Esboza la combinación de dos procedimientos de la comunicación: codificación y descodificación, y atiende de manera especial a la ostensión y la inferencia para llamar la atención del interlocutor, mostrándole algo por medio del lenguaje verbal y no verbal. Un mismo enunciado resultará o no relevante según el contexto, pues los hablantes harán deducciones que les permitirán una interpretación adecuada. Se trata de interpretar lo que el emisor quiere transmitir atendiendo a lo implícito de un enunciado más que a su significado literal.

Anscombre y Ducrot (1994 [1983]) desarrollan desde finales del pasado siglo la teoría de la argumentación lingüística, extendida hasta los estudios más recientes de Ducrot y Carel (2005). En esencia, resalta el uso de morfemas y conectores que aportan mayor fuerza al discurso argumentativo y postula que nuestras palabras albergan siempre un valor argumentativo, dado que el uso de la lengua tiene un carácter fundamentalmente argumentativo. Se trata de una teoría pragmática desarrollada en cuatro etapas: el descriptivismo radical, donde la relación entre la lengua y la argumentación es mínima y se entiende esta última en un sentido retórico; el descriptivismo presuposicional, en el que la lengua adquiere cierta relevancia en relación con la argumentación y es la que determina los hechos que intervienen en ella; la argumentación como un elemento constitutivo de la significación, al concebir que la lengua contiene valores descriptivos, pero también valores argumentativos intrínsecos, donde se resalta además una relación binaria argumento-conclusión, y, la cuarta etapa, del argumentativismo radical, donde se considera que los hechos que describe la lengua no son más que la cristalización de movimientos argumentativos, y existe una relación triádica: argumento-principio-conclusión.

La aportación de van Eemeren y Grootendorst (2004), tras unos trabajos iniciales en los que analizan el funcionamiento comunicativo de la argumentación como una constelación de enunciados y se ocupan del funcionamiento de las falacias (van Eemeren y Grootendorst 1992), consiste en una nueva forma de analizar y valorar argumentos, que denominan pragma-dialéctica. Esta propone un modelo de discusión, basado en diez reglas, que implica un planteamiento de la argumentación más como habilidad pragmática y dialéctica que como operación lógica a la manera de la tradición clásica.

En efecto, los estudios sobre la argumentación se remontan a la retórica clásica, pero, tras su decadencia de siglos hasta acabar convertida en una estilística, se refundaron en la segunda mitad del siglo xx con la llamada nueva retórica. Sus representantes, Perelman y Olbrechts-Tyteca (1988 [1958]), Toulmin (2007 [1958]) y Anscombre y Ducrot (1994), consideraron el lenguaje como un instrumento de persuasión diseñado para convencer. Para la teoría de la argumentación lingüística, todo enunciado tiene una capa- 
cidad argumentativa, de tal manera que su significado favorece ciertas conclusiones a las que se puede arribar. En la misma línea se sitúa el trabajo de Fuentes y Alcaide (2007), centrado en establecer las formas de expresión de la argumentación lingüística a través del análisis del concepto mismo de argumentación, así como de sus elementos, estructuras y mecanismos.

Otra aportación, en este caso de la etnografía lingüística, al estudio de la comunicación humana que es de utilidad para el estudio del lenguaje jurídico es la noción de evento comunicativo (speech event). Este aparece como una unidad de análisis desde el modelo SPEAKING de Hymes (1984), integrado por ocho componentes que coinciden con las iniciales del término inglés en forma de acróstico: $\mathrm{S}$ (situación), $\mathrm{P}$ (participantes), $\mathrm{E}$ (ends: finalidades), A (actos), K (key: clave), I (instrumentos), N (normas) y G (género). El evento comunicativo constituye una forma de organizar las interacciones, compuestas por unidades estructurales del hablar.

La interacción comunicativa de abogados, fiscales y jueces durante el juicio oral manifiesta características sui generis en cuanto a sus elementos compositivos. La situación o localización espacio-temporal del hecho comunicativo judicial se contextualiza en una sala de vistas donde se desarrolla el juicio oral, cuyas formalidades son diferentes a otros espacios comunicativos. Los participantes requieren de un dominio técnico del derecho que les permita una adecuada impartición de justicia, ya sean letrados o miembros del tribunal. La finalidad es llegar a la obtención de una sentencia como documento de carácter vinculante, a través de actos precedentes que tienen un orden y una estructura variables en cada sistema judicial. La clave o tono de la interacción y el grado de formalidad del discurso jurídico están regidos por las reglas de la oratoria forense y por normas de interacción e interpretación que regulan la toma de la palabra y permiten inferir tanto lo dicho como lo no dicho por el juez y por las partes litigantes. Todos emplean instrumentos verbales y no verbales apropiados para el desarrollo del juicio, el cual, como género o tipo de interacción social, resulta peculiar, con secuencias discursivas expositivas, narrativas y, sobre todo, argumentativas que tributan a la exposición de un alegato oral trascendente al fallo judicial.

En síntesis, entre las aportaciones de las teorías lingüísticas examinadas hay que anotar que permiten comprender el funcionamiento del lenguaje jurídico y de los eventos comunicativos en que este se utiliza, considerando tanto el elemento verbal y no verbal como el contexto sociocultural y cognitivo. El uso del lenguaje jurídico requiere estudios minuciosos de su funcionamiento de modo que este análisis sea aplicado a la mejora práctica de la competencia comunicativa en el contexto judicial. 


\section{De LA RETÓRICA CLÁSICA A LA TEORÍA DE LA ARGUMENTACIÓN JURÍDICA}

En la historia evolutiva del derecho, el análisis de qué argumentos emplear y de qué modo para la solución de los conflictos es lo que ha dado paso en la actualidad a la llamada teoría de la argumentación jurídica (TAJ). Sus antecedentes se remontan a la antigüedad clásica, donde el aprendizaje del arte de la palabra ocupaba un lugar destacado en la formación de los hombres libres por su utilidad en la vida pública y por ser concebida como forma de alcanzar la bondad y la verdad.

El nacimiento de la retórica está ligado a la aparición del pensamiento filosófico y al desarrollo de la vida pública. La elocuencia -el dominio del lenguaje- era el elemento distintivo del hombre culto y, por lo tanto, imprescindible para participar en la actividad ciudadana. Su invención como técnica de la argumentación se atribuye a Tisias y Córax en el siglo v a. C. cuando, tras el derrocamiento de la tiranía, los ciudadanos sicilianos emprendieron una larga serie de procesos para recuperar sus tierras y ambos autores compusieron para este fin un libro de preceptos o arte mediante el cual se enseñaba, sobre todo, la técnica de la oratoria judicial.

Su desarrollo inicial se debe en gran parte a los sofistas y sobre todo a Gorgias, cuyo objetivo era dotar a la palabra de utilidad práctica y que logró por esta vía convertir la retórica en una parte fundamental de la paideia, el programa pedagógico del joven griego (Jaeger 1967 [1933]³; Hernández y García 1994; Mortara 1996; López Eire 2000; García García 2005).

Posteriormente, Platón en Fedro [2009] y, sobre todo, Aristóteles en su Retórica [1990] pusieron los cimientos filosóficos de la disciplina. En el libro I, la Retórica de Aristóteles establece que para la composición de cualquier tipo de discurso -deliberativo (cap. 4), demostrativo o epidíctico (cap. 9) o forense (cap. 10)- hay que tener en cuenta una serie de elementos invariables -el auditorio, del que se ocupa en el capítulo 3; el tema, objeto de los caps. 4, 9 y 10, y las características del orador (cap. 2)- y seguir cinco fases que aún hoy siguen vigentes en la formación de juristas:

1. Heuresis o inventio, en la que se reúnen temas o subtemas y los argumentos que los van a sostener (Libro I).

2. Taxis o dispositio. En esta fase, que Aristóteles desarrolla en los capítulos finales del Libro III de la Retórica, se organiza el contenido y se establece el orden de presentación de temas y argumentos.

\footnotetext{
${ }^{3}$ Señala Jaeger (1967), a propósito del Gorgias de Platón, que la vinculación entre retórica y política es tan evidente en la antigua Grecia, que lo fundamental no era tanto definir esta téchne, sino el hecho de poner de manifiesto que «confiere un poder a quien la domina» (1967: 513).
} 
3. Lexis o elocutio. Fase de elección del tipo de lenguaje: variedad lingüística y estilo (Libro III, caps. 1-12).

4. Mneme o memoria. Consiste en recordar los temas, su orden de presentación y los recursos que se usarán (Libros I y III).

5. Hypocrisis, actio o pronuntiatio. Explicada en los capítulos finales del Libro III, no es otra cosa que la preparación para actuar verbalmente.

En Roma, la retórica no floreció hasta el siglo I a. C., cuando Grecia se convirtió en provincia romana. El rhetor pretendía formar al orador perfecto y enseñaba sobre todo el arte de la palabra en el seno de la humanitas. Sin duda, entre las figuras romanas destacadas hay que citar a Quintiliano, quien en Institutio oratoria recoge sus ideas sobre la formación del orador entendida como una formación integral del ciudadano en la que concurren todas las cualidades ético-políticas. El arte de la retórica persigue para Quintiliano (III 5, 1) cuatro fines -agradar, instruir, emocionar y persuadir- y para desarrollarlo es necesario un aprendizaje largo y laborioso basado en el estudio de piezas maestras de grandes autores y en su imitación ${ }^{4}$. Para Quintiliano, la palabra es la base de la vida social y de las instituciones que la organizan, lo cual resalta la importancia de la retórica para las clases influyentes a las que él formaba y explica que esta se orientase hacia la práctica. Sin embargo, cabe señalar que en su tiempo -durante el Imperio- ya no se daban las condiciones esenciales de libertad que garantizan el florecimiento de la retórica, la cual, encerrada en las escuelas, se redujo a las declamaciones y al aprendizaje de preceptos, abandonando su carácter interdisciplinar y su índole filosófica.

Según Atienza (2004), las dos grandes contribuciones de la antigüedad al estudio de la teoría de la argumentación las constituyen las obras de Aristóteles [1990] y Cicerón [2013]. El primero, con su caracterización de los argumentos dialécticos, es reconocido como el padre de la teoría antigua de la argumentación y de la lógica formal; el segundo, jurista, destaca por formular un catálogo de tópicos (topoi) de aceptación generalizada.

Durante la Edad Media, la retórica se hizo más sofisticada. Era utilizada en disímiles situaciones, y recurría a todo tipo de técnicas orales, gesticulares, corporales. Tenía por objetivo impresionar al interlocutor, lograr persuadirlo; intención esta que, aunque no se hubiese declarado expresamente, se convertiría después en uno de los objetivos del debate judicial. No obstante, se inicia aquí el camino de su decadencia y, como señala Abascal:

\footnotetext{
4 «De éstos y de los demás autores, dignos de ser leídos, se ha de tomar tanto la riqueza de palabras como la variedad de las figuras y el método de construir las frases; después hay que dirigir la atención al modelo de todas las excelencias literarias. Pues no puede dudarse de que una gran parte del arte se fundamenta en la imitación» (Quintiliano, X, 2, 1).
} 
La Retórica, sorprendentemente, también abandonó la oralidad, dirigida más a los recursos para embellecer el lenguaje, oral o escrito, y cada vez menos a una reflexión sobre el conjunto de elementos que intervienen en la configuración de un discurso. (Abascal 2004: 118)

De esta forma, la palabra retórica acaba adquiriendo el sentido coloquial de lenguaje adornado y grandilocuente que muchas veces es asociado al rol del abogado en el estrado, sobre todo para quienes, erróneamente, contemplan el juicio oral como un acto teatral y el alegato forense como un guion que desarrolla el jurista como si fuese un mero actor.

En la actualidad existe una recuperación de los estudios de retórica desde diversos campos ${ }^{5}$. A decir de Mortara (1988: 11), «actualmente el crecimiento de los estudios retóricos ha originado sugerentes alianzas: ante todo con los estudios jurídicos, en la línea de la más antigua vocación retórica». De tales alianzas resulta la teoría de argumentación jurídica, enraizada en la retórica, y dirigida a investigar de manera rigurosa la estructura del razonamiento y de la argumentación. Sobre su génesis se plantea lo siguiente:

La conocida actualmente como Teoría de la Argumentación Jurídica tiene su origen en los años 50 del siglo xx, cuando se rechaza la lógica formal para analizar razonamientos jurídicos. Así aparece la Teoría de la Argumentación Jurídica en el siglo xx, constituida por aquellos estudios jurídico-filosóficos que esgrimen las diversas corrientes de pensamiento respecto al contenido de las premisas argumentativas, desde la perspectiva de los operadores del Derecho. (Atienza 2004: 2)

La evolución de esta teoría ha transcurrido por tres etapas. La primera se inicia en 1950, con los estudios de Levi (1964 [1949]), Viehweg (1993 [1953]), Toulmin (2007 [1958]), Perelman y Olbrechts-Tyteca (1988 [1958]) o Recaséns (1965), precursores de la TAJ, que tienen en común el rechazo de la lógica deductiva para resolver problemas jurídicos. El segundo período arranca en 1958, con la teoría estándar de la argumentación jurídica, cuyos principales representantes son Alexy (1989 [1978]), MacCormick (1978) y Summers (2001). La tercera etapa, a partir de los años noventa, es la de la Nueva TAJ ${ }^{6}$, cuyo máximo exponente es Atienza (2004) y entre

${ }^{5}$ La conocida como nueva retórica encuentra sus máximos exponentes en diferentes áreas de las ciencias, tales como la semiótica textual (Eco y Greimas), la orientación retórica de los estudios semiológicos sobre la imagen (Barthes, Durand y el Grupo $\mu$ ), la publicidad (Lomas) y la propia teoría de la argumentación jurídica (Perelman y Olbrechts-Tyteca). Vid. Lomas (2014: 53). En España es destacable el trabajo de Fuentes y Alcaide (2007) sobre los medios de expresión de la argumentación lingüística.

${ }^{6}$ A decir de Vázquez (2008), el surgimiento de la TAJ en la segunda mitad del siglo XX está dado por la trascendencia de la II Guerra Mundial para el derecho. En este contexto histórico pierden sentido los dogmas del Estado y toda decisión de poder que afecte a los 
cuyos seguidores destacan Moreso (2006), Porto (2008), Salas (2010), Ureta (2010) y Vázquez (2008).

Así, para Perelman y Olbertchs-Tyteca (1988 [1958] $)^{7}$ argumentar no consiste tanto en ofrecer buenas razones en apoyo de una idea o una decisión, sino más bien en persuadir afectivamente al perceptor. De aquí que estos autores expliquen la argumentación como un conjunto de técnicas destinadas a lograr la adhesión a una tesis por parte de un auditorio, en tanto elabora una lógica para los juicios de valor que resulta indispensable para el análisis del razonamiento práctico.

Viehweg (1986 [1953]) también coincide con que la argumentación es un proceso retórico, persuasivo, en el que los tópicos sirven como fuente de los argumentos. Es una técnica del pensamiento problemático, una búsqueda y un examen de premisas que puede emplear tópicos o puntos de vista ya dados.

La aportación de Toulmin (2007 [1958]) incluye un nuevo concepto, los diagramas de argumentación en el debate jurídico-político, que cuentan con sólidos componentes de lógica formal e investigación empírica. Los topoi son los principios que permiten explicar el valor argumentativo del enunciado en forma de creencias comunes, de proverbios, lemas, eslóganes o ideas preconcebidas. El diagrama de Toulmin ha servido como punto de partida para representar la estructura de argumentos rebatibles; en él se bosquejan los debates como árboles en los que el tema central es el tronco y los temas subsidiarios son ramas. Este diagrama puede comprenderse como una herramienta lógica para el análisis de estructuras normativas de argumentación jurídica, pese a que tiene limitaciones en casos de razonamiento práctico cuya finalidad es persuadir a un auditorio variado.

La necesidad de analizar el derecho en cada caso concreto es una de las ideas centrales de Recaséns (1965). Cada caso es diverso y por ello el derecho es esquivo a las generalizaciones, las sistematizaciones y los métodos de la ciencia. Afirma que hasta el momento de su aplicación las leyes son siempre una obra inconclusa, abriendo paso con ello a la interpretación extensiva.

En general, las teorías de la argumentación jurídica de los años cincuenta impugnan la concepción formalista de la aplicación del derecho. Se muestran escépticas frente a la lógica deductiva y rescatan modelos de argumentación clásicos (topoi, retórica, dialéctica). Pese a su valor como precursoras, fueron criticadas por prescindir de la lógica para el razonamiento jurídico.

ciudadanos necesita justificaciones no solo alejadas de la deducción silogística, sino de cualquier fundamentación autoritaria.

${ }^{7}$ Perelman y Olbrechts-Tyteca (1988 [1958]) superan la visión de la retórica como arte o tratado de la persuasión, carente de contenido filosófico alguno. Reaccionan contra la reducción de la retórica clásica a una especie de estilística y restablecen la importancia de la retórica antigua como fundamento para una lógica de los juicios del valor. 
A partir de 1958, los representantes de la teoría estándar de la argumentación jurídica coinciden en denunciar las insuficiencias de la lógica formal y en buscar esquemas para valorar los argumentos empleados por los decisores judiciales. Dos obras clave de esta etapa son la Teoría de la argumentación jurídica, de Alexy, y Legal Reasoning and Legal Theory, de MacCormick, ambas de 1978. Con ellas sus autores superaron todo el cuerpo de teorías precursoras e influyeron poderosamente sobre los trabajos de otros como Aarnio (2010) o Atienza (2004).

MacCormick delinea una teoría integradora de la argumentación jurídica, reconociendo que esta tiene una función esencialmente justificadora, pues persuade mediante razones; en cuanto a sus efectos, es una argumentación consecuencialista, consciente de los resultados que generará. Alexy resalta el carácter procedimental de la argumentación (un argumento es válido solo si es resultado de un procedimiento) y plantea además que la argumentación jurídica se logra a través del discurso jurídico, el cual está limitado por la doctrina, la ley y el precedente que, a su vez, le conceden tipicidad.

Estos autores han puesto de manifiesto insistentemente las insuficiencias que presentan tanto una concepción puramente formalista del razonamiento jurídico (que reduce la aplicación del derecho a un silogismo) como una concepción irracionalista (que la reduce a simples expresiones de emociones). Se sitúan en un punto medio que parte de la posibilidad de un análisis racional de los procesos argumentativos, pero también reconocen las limitaciones que este análisis presenta en el derecho. Para ambos es incuestionable que la justificación de las decisiones jurídicas, su racionalidad, es una pieza clave. Este análisis complementa la posición de que no hay debate sin argumentos, no hay actividad discursiva sin actividad argumentativa debido al modo en que los argumentos dinamizan el debate jurídico.

Los estudios revisados hasta ahora se han basado en una preocupación constante del derecho: cómo justificar (argumentar) una decisión de poder. A esta razón se suma, en la década de los noventa del siglo xx y en el marco de nueva TAJ, la aportación de Atienza (2004), para quien existen tres formas de entender la argumentación jurídica: la formal, la material y la pragmática. Para la lógica formal lo que se logra es una inferencia, los argumentos son proposiciones a través de las premisas y la conclusión, o sea, mediante el razonamiento silogístico. Para la posición material, lo trascendente es que las premisas sean válidas; lo importante no es la técnica para inferir proposiciones, sino la veracidad de las premisas. Por último, la visión pragmática percibe la argumentación como una interacción lingüística, pues es desarrollada por dos sujetos con el objetivo de lograr el convencimiento de uno sobre otro ${ }^{8}$. Esta etapa es la más fecunda para

\footnotetext{
${ }^{8}$ Se establece aquí un importante punto de contacto entre el derecho y las ciencias del lenguaje.
} 
el análisis teórico-filosófico de los procesos argumentativos y comunicativos en general que tienen lugar en el derecho.

Atienza concibe el derecho como una actividad argumentativa que guarda estrecha relación con el lenguaje, la lógica, la tópica, la retórica y la dialéctica. Sus teorías se basan en fundamentos filosóficos antikelsenianos, pues muestran que el derecho es más que norma y solo norma, es una actividad práctica, incluso más, una especie dentro del género amplio de la argumentación práctica. De esta forma, el máximo exponente de la argumentación jurídica práctica en un escenario de litigación es el juicio oral. Este último aparece como el debate jurídico o proceso de comunicación jurídica por antonomasia.

Los representantes de la TAJ en esta etapa coinciden en que su objeto de estudio es la argumentación entendida como acción y efecto de argumentar, en tanto «argumentar es dar razones que justifiquen un determinado enunciado» (Vázquez 2008: 117). El término contiene la frecuente ambigüedad proceso-producto, ya que a la vez significa actividad, pero también es el resultado de ella. No obstante, se presenta más bien como producto, pues no se argumenta algo, sino a favor o en contra de algo.

En sus últimas elaboraciones se reconocen dos enfoques esenciales de la TAJ: el descriptivo, centrado en el análisis de cómo argumentan los juristas, y el prescriptivo, orientado al estudio de cómo deberían argumentar. Existe, a su vez, una triple perspectiva sobre ella: la empírica, la normativa o valorativa, y la conceptual o analítica. La primera pretende describir las decisiones jurisdiccionales, la valorativa intenta aportar fórmulas para mejorar la argumentación, mientras la perspectiva analítica es la más aceptada entre los teóricos pues persigue conceptualizar y sistematizar la argumentación jurídica, lo que la convierte en una reconstrucción racional y sistémica de las prácticas argumentativas del derecho. La TAJ, abordada desde la perspectiva analítico-conceptual, ostenta como mérito el lograr un equilibrio entre las concepciones formalistas y las irracionalistas, entre la lógica y la retórica, centrando su objeto en las formas ontológica y deontológica de argumentar por parte de los juristas. Quizás la crítica más frecuente que se le hace es que la gran mayoría de los teóricos la han ceñido solo a la materia judicial, cuando no son los jueces los únicos juristas litigantes que argumentan.

Cabe mencionar, por último, otra contribución de los más recientes estudiosos de la argumentación jurídica, y es la definición misma del concepto, en la que hay bastante unanimidad. Grosso modo, Salas y Moreso se centran en los mismos elementos: argumentación y caso judicial. Para Salas (2010: 86), la argumentación jurídica «consiste en la exposición de un discurso oral por medio del cual se pretende justificar determinada decisión judicial en un contexto adversarial»; para Moreso (2006: 118), «es todo 
aquel esquema de argumentación que tienda a resolver un caso difícil». Interesante y más complejo análisis realiza Porto (2008), quien justifica por qué en la actualidad es esencial la argumentación jurídica: mientras que la interpretación jurídica se limita a buscar soluciones, la argumentación jurídica pretende justificar razones a través de esquemas de argumentos, los cuales se vislumbran en el proceso comunicativo que tiene lugar durante el juicio oral.

En la actividad comunicativo-lingüística que es la argumentación oral pone el acento Boris (2015: 28) al señalar que «argumentar se convierte en una actividad lingüística, y un argumento, en consecuencia, es un producto lingüístico que se consigna en un conjunto de enunciados».

Sin duda, el uso adecuado de la argumentación jurídica va aparejado al desarrollo eficiente de la competencia comunicativa y, en especial, de la oral. No se puede separar lo argumentativo de lo lingüístico, ni lo jurídico de lo comunicativo. Ser un jurista litigante competente requiere, en primera instancia, el uso adecuado del lenguaje jurídico, y a su vez exige ajustarse al contexto judicial concreto. Empleando el razonamiento lógico y las estrategias persuasivas se logrará entonces la absolución o la condena del encausado, cuyos derechos son exigibles gracias al despliegue de efectivas competencias comunicativas que incluyen la argumentación jurídica.

\section{A MODO DE CONCLUSIÓN}

La competencia oral constituye un conjunto de capacidades de integración de conocimientos, habilidades y aptitudes que un hablante desarrolla durante la interacción social en un contexto determinado; en el derecho, tales capacidades son esenciales para el ejercicio profesional de la jurisprudencia.

El estudio de la praxis del lenguaje jurídico debe centrarse en sus dos elementos constitutivos esenciales: la competencia oral y la argumentación, y para ello debe recurrir a aportaciones de las más recientes ciencias del lenguaje y de las teorías de la argumentación de cuño neorretórico. De aquí pueden derivarse propuestas que completen la formación de los juristas para el ejercicio de su profesión integrando pautas y ejercitaciones destinadas a estructurar el razonamiento de iure y a mejorar el dominio de la oralidad en todas sus dimensiones. Estas deben basarse en sólidos fundamentos científicos, algunos de los cuales se han revisado aquí, y en estudios experimentales -tanto cuantitativos como cualitativos- destinados a obtener datos sobre qué dominio de estas destrezas presentan en la actualidad los egresados de derecho, estudios cuya necesidad se deriva también, a modo de prospectiva investigadora, de este trabajo. 


\section{BIBLIOGRAFÍA}

AARNIO, Aulis (2010): «Perelman y la idea del argumento moral». En Aulis Aarnio, Manuel Atienza y Francisco J. Laporta, Bases teóricas de la interpretación jurídica, México: Fontamara.

Abascal, M. ${ }^{a}$ Dolores (2004): La teoría de la oralidad, Anejo XLIX de Analecta Malacitana, Universidad de Málaga: Málaga.

Alexy, Robert (1989 [1978]): Teoría de la Argumentación Jurídica. La teoría del discurso racional como teoría de la fundamentación jurídica. Traducción de Manuel Atienza e Isabel Espejo, Madrid: Centro de Estudios Constitucionales.

Anscombre, Jean-Claude y Oswald Ducrot (1994): La argumentación en la lengua, Madrid: Gredos. Versión española de Julia Sevilla y Marta Tordesillas.

ARISTÓteles [1990]: Retórica. Edición, traducción, prólogo y notas de Antonio Tovar, Madrid: Centro de Estudios Constitucionales.

Atienza, Manuel (2004): Las razones del Derecho. Teorías de la Argumentación Jurídica, México: Universidad Nacional Autónoma de México.

BORIs, Yuliet (2015): «La argumentación jurídica de las sentencias civiles en Cuba», Revista de la Abogacía. Boletín ONBC 53, 200-208.

Canale, Michael y Merrill Swain (1996): «Fundamentos teóricos de los enfoques comunicativos», Signos 17 y 18, 54-62 y 78-89.

CAREL, Marion y Oswald Ducrot (2005): La semántica argumentativa. Una introducción a los bloques semánticos. Edición de Marta García y Alfredo Lescano, Buenos Aires: Colihue Universidad.

Cicerón, Marco Tulio [2013]: El orador. Traducción de Eustaquio Sánchez Salor, Madrid: Alianza.

DELORS, Jacques (1997): La educación encierra un tesoro. Informe a la UNESCO de la Comisión Internacional sobre la Educación para el Siglo XXI, Ediciones UNESCO. $<$ http://www.unesco.org/education/pdf/delors_s.pdf $>$.

Ducrot, Oswald (1986): El decir y lo dicho. Polifonía de la enunciación. Traducción de Irene Agoff, Barcelona: Paidós.

DumaIs, Christian (2012): «Vers une progression des objets d'enseignement/ apprentissage de l'oral qui s'appuie sur le développement des élèves». En Réal Bergeron et Ginette Plessis-Bélair (dir.), Représentations, analyses et descriptions du français oral, de son utilisation et de son enseignement au primaire, au secondaire et à l'université, Côte Saint-Luc: Éditions Peijac, 9-34.

Fuentes, Catalina y Esperanza AlCAIDE (2007): La argumentación lingüistica y sus medios de expresión, Madrid: Arco/Libros.

GumPerz, John y Dell Hymes (1972): Directions in Sociolinguistics. The ethnography of communication, New York: Basil Blackwell.

Hernández, José Antonio y M. ${ }^{a}$ Carmen García (1994): Historia breve de la retórica, Madrid: Síntesis. 
Hymes, Dell (1984): Vers la compétence de communication, París: Hatier.

JAEger, Werner (1967 [1933]): Paideia. Los ideales de la cultura griega. Traducción de Joaquín Xirau (libros I y II) y Wenceslao Roces (libros III y IV), México D.F.: FCE.

LEVI, Edward (1964 [1949]: Introducción al razonamiento jurídico. Traducción de Genaro R. Carrió, Buenos Aires: Eudeba.

Lomas, Carlos (2014): La educación lingüistica, entre el deseo y la realidad: competencias comunicativas y enseñanza del lenguaje, Barcelona: Octaedro.

MACCoRmick, Neil (1978): Legal reasoning and legal theory, Oxford: Clarendon Press.

Moreso, Josep Joan (2006): Lógica, argumentación e interpretación en el derecho, Barcelona: UOC.

Mortara, Bice (1988): Manual de Retórica. Traducción de M. José Vega, Madrid: Cátedra.

NúÑEZ, Pilar (2003): Didáctica de la comunicación oral. Bases teóricas y orientaciones metodologicas para el desarrollo de la competencia discursiva oral en la educación obligatoria, Granada: GEU.

ONG, Walter (1987): Oralidad y escritura. Tecnologías de la palabra. Traducción de Angélica Scherp, México: FCE.

Perelman, Chaim y Lucie Olbrechts-Tyteca (1988 [1958]): Tratado de la argumentación. La nueva retórica. Traducción de Julia Sevilla, Madrid: Gredos.

Plantin, Christian (1996): L'argumentation, París: Éditions Du Seuil.

Platón [2009]: Fedro. Edición bilingüe, introducción y notas de Luis Gil Fernández. Actualización bibliográfica de A. Silván Rodríguez. Madrid: Dykinson.

PorTo, Deivti Dimitros (2008): «Necesidad de enseñanza de la teoría y práctica de la argumentación jurídica en las Facultades de Derecho de Brasil», Revista de la Facultad de Ciencias Sociales y Jurídicas de Elche I/3, 210-229.

Quintiliano de CaLahorra (2000): Obra completa. Tomo IV. Sobre la formación del orador. Libros X-XII. Edición bilingüe latín-español. Traducción y comentarios de Alfonso Ortega Carmona, Salamanca: Publicaciones de la Universidad Pontifica de Salamanca y Caja Duero.

Recaséns, Luis (1965): Tratado General de Filosofía del Derecho, México: Porrúa.

SALAS, Christian (2010): Trascendencia de las técnicas de litigación oral en el proceso penal. Apreciaciones a partir de la vigencia del Código Procesal penal de 2004, Lima: Librería y Ediciones Jurídicas.

SPERBER, Dan y Deirdre Wilson (1986): La relevancia. Comunicación y cognición. Traducción de Eleanor Leonetti, Madrid: Visor.

Summers, Robert (2001): La naturaleza formal del Derecho. Traducción de Pablo Larrañaga, Fontamara: México.

Tовón, Sergio (2010): Formación integral y competencias. Pensamiento complejo, currículo, didáctica y evaluación, Bogotá: Ecoe Ediciones.

Toulmin, Stephen (2007 [1958]): Los usos de la argumentación. Traducción de María Morrás y Victoria Pineda, Madrid: Península.

Ureta, Juan Antonio (2010): Técnicas de Argumentación Jurídica para la litigación oral y escrita, Lima: Jurista Editores. 
VAn EEmeren, Frans y Robert Grootendorst (1992): Argumentation, communication, and fallacies, Hillsdale, NJ: Lawrence Erlbaum.

- y - (2004): A systematic theory of argumentation: the pragma-dialectical approach, New York: CUP.

VÁZQUEZ, Omar (2008): Teoría de la argumentación jurídica sobre la justificación de las decisiones judiciales, México: UAT-Gudiño Cicero.

VIEHWEG, Theodor (1993 [1953]): Topics and law, Fráncfort: Peter Lang.

Weston, Anthony (2011 [1987]): Las claves de la argumentación. Traducción de Mar Vidal, Barcelona: Ariel. 